\title{
Approach to the Assessment of Vocal Cord Movement by Ultrasonography
}

\author{
Oktay İrkörücü ${ }^{1}$
}

Published online: 20 September 2017

(C) Société Internationale de Chirurgie 2017

To the Editor,

We read with great interest the article by Fukuhara et al. [1], whose work shows that when compared with the conventional middle transverse procedure, the lateral vertical procedure improved the rate of visualization of vocal cord movement by ultrasonography. They are suggesting that it is a useful technique to screen for vocal cord paralysis.

Although the study is attractive, we think that some issues are not adequately addressed in this article. We would like to express our opinion, based on three important questions. First, what are the positive and negative predictive values for both ultrasonography methods? Second, what are the sensitivity, specificity and accuracy values for each method? Third, which ultrasonographic criteria were used to clearly distinguish between vocal cords paresis and paralysis?

Ultrasonography is not a new modality; general surgeons in some developed countries embraced it as a diagnostic tool and an extension of the physical examination. Considering the limitations of practitioners other than the radiologist, in practice, we believe that the use of both ultrasonography methods may be more useful than the use of only one ultrasonography method. On the other hand, it is not possible to detect every type of vocal cord damage by ultrasonography [2]. Ultrasonography should be considered as an adjunctive method with limitations in the evaluation of vocal cords. We would like to emphasize that direct laryngoscopy is still the most valuable and indispensable method in evaluating vocal cords in today's conditions.

\section{Compliance with ethical standards}

Conflict of interest The author declares that no competing financial interests exist.

\section{References}

1. Fukuhara T, Donishi R, Matsuda E, Koyama S, Fujiwara K, Takeuchi H (2017) A novel lateral approach to the assessment of vocal cord movement by ultrasonography. World J Surg. doi:10. 1007/s00268-017-4151-z

2. Woo JW, Suh H, Song RY, Lee JH, Yu HW, Kim SJ, Chai YJ, Choi JY, Lee KE (2016) A novel lateral-approach laryngeal ultrasonography for vocal cord evaluation. Surgery 159(1):52-56
Oktay İrkörücü

oktaytip@yahoo.com

1 Department of General Surgery, Adana Health Research and Training Center, Sağlık Bilimleri University, Adana, Turkey 